Check for updates

Cite this: J. Anal. At. Spectrom., 2019 34,2440

Received 16th July 2019

Accepted 29th October 2019

DOI: 10.1039/c9ja00249a

rsc.li/jaas

\section{Lipid-soluble arsenic species identified in the brain of the marine fish skipjack tuna (Katsuwonus pelamis) using a sequential extraction and HPLC/ mass spectrometry $\dagger$}

\author{
Michael Stiboller, (D) a Fabiana P. Freitas, (D) ${ }^{b}$ Kevin A. Francesconi, (D) ${ }^{a}$ \\ Tanja Schwerdtle, (D) ${ }^{c}$ António J. A. Nogueira DD $^{b}$ and Georg Raber (D)*a
}

\begin{abstract}
Lipid-soluble arsenicals, so called arsenolipids, occur in appreciable quantities in various marine organisms including fish. In this study, arsenolipids as well water-soluble arsenic species were investigated in brain (9.1-17.4 mg As per kg; dry mass) and muscle (4.0-5.8 mg As per kg; dry mass) tissues in five specimens of the marine fish skipjack tuna (Katsuwonus pelamis). For this purpose, we developed a sequential extraction method whereby the freeze-dried tissue was first treated with pyridine (organic extract) followed by aqueous ammonium bicarbonate (water extract) to extract arsenolipids and water-soluble species, respectively. When the method was applied to the tuna tissues, the arsenic distribution for brain was $55 \%$ (organic extract), 30\% (water extract) and 15\% (pellet), whereas for muscle tissue the corresponding values were $20 \%, 55 \%$, and $25 \%$. Arsenic species in water and organic extracts of muscle and brain tissues were investigated by HPLC/mass spectrometry. For both tissues, the water extracts contained arsenobetaine as the major arsenic species together with small amounts of dimethylarsinate and trimethylarsine oxide; trace amounts of dimethylarsinoyl propionic acid were found only in brain tissues. Arsenic-containing hydrocarbons (AsHCs), were the major arsenolipids in both tuna brain and muscle. The arsenolipid content in brain ranged from $3.8-5.9 \mathrm{mg}$ As per $\mathrm{kg}$, whereas it was substantially lower in muscle $(0.3-0.8 \mathrm{mg}$ As per $\mathrm{kg}$ ) reflecting arsenolipids' potential to cross the blood brain barrier and accumulate in the fish brain.
\end{abstract}

\section{Introduction}

Marine organisms can contain arsenic at levels of up to and above $100 \mathrm{mg}$ As per $\mathrm{kg}$ (dry mass) comprising mainly watersoluble organic arsenic species, such as arsenobetaine $(\mathrm{AB})$ in fish and arsenosugars in algae. Besides the water-soluble arsenic species, marine organisms can also contain appreciable quantities of lipid-soluble arsenic often constituting 10$30 \%$ of the total arsenic content, ${ }^{1}$ or even higher in fatty fish such as sashimi tuna, ${ }^{2}$ or in lipid-rich organs of marine fish. ${ }^{3}$

Although lipid-soluble arsenic in cod-liver was first reported in $1928,{ }^{4}$ the identity of the arsenic compounds remained unknown until the first structural elucidation of an arsenosugar phospholipid in 1988 by Morita and Shibata. ${ }^{5}$ Since then more than 100 arsenolipids have been identified, all of them in the last 11 years following improvements in analytical techniques

Institute of Chemistry, Analytical Chemistry NAWI Graz, University of Graz, Universitätsplatz 1/I, 8010 Graz, Austria.E-mail: georg.raber@uni-graz.at

${ }^{b}$ Department of Biology \& CESAM, University of Aveiro, 3810 Aveiro, Portugal

'University of Potsdam, Institute of Nutritional Sciences, Food Chemistry, ArthurScheunert-Alle 114-116, 14558 Nuthetal, Germany

$\dagger$ Electronic supplementary information (ESI) available. See DOI: 10.1039/c9ja00249a for their detection and identification. ${ }^{6}$ Arsenolipids range from simple compounds like arsenic fatty acids ${ }^{7}$ (AsFAs, Fig. 1) and arsenic hydrocarbons ${ }^{8}$ (AsHCs, Fig. 1) to more structurally complex lipid arsenicals, such as arsenic-containing phosphatidylcholines ${ }^{9}$ (AsPCs, Fig. 1) or a newly discovered arseniccontaining phytol. ${ }^{10}$ Arsenolipids occur in various marine sources, such as fish oils, ${ }^{11,12}$ seal oil, ${ }^{11}$ fish tissues, ${ }^{2,13-15}$ algae ${ }^{16-18}$ and fish roe, ${ }^{9}$ but they have not yet been detected in a terrestrial organism.

Arsenolipids are currently under investigation with regard to human health, as recent research demonstrated that some arsenolipids are toxic to cultured human cells ${ }^{19}$ and also showed toxicity in the in vivo model Drosophila melanogaster. ${ }^{20}$ In the in vitro Caco-2 intestinal barrier model, ${ }^{21}$ AsHCs transferred efficiently across this barrier towards the blood-facing side and showed a high intestinal bioavailability, suggesting that AsHCs have the potential to cross physiological barriers. In a first study ${ }^{22}$ with a living organism, the fruit fly Drosophila melanogaster, it was shown that the arsenolipid AsHC 332 accumulated in the brain of the fly. It is currently unknown, however, if arsenolipids are also able to cross the blood-brain barrier in higher organisms. 
<smiles>C[As](C)(=O)CCCCCCCCCCCCCC(=O)O</smiles><smiles>CCCCCCCCCCCCCCC[Si](C)(C)=O</smiles>

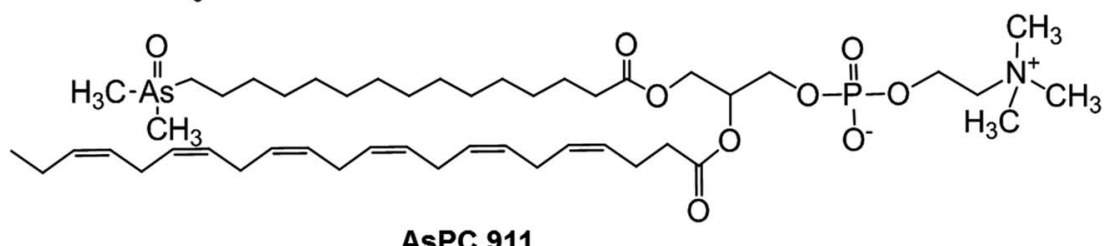

AsPC 911

Fig. 1 Examples of structures of three known arsenolipid classes found in different marine organisms: AsFA = arsenic fatty acid, AsHC = arsenic hydrocarbon, \& AsPC = arsenic-containing phosphatidylcholine. The compounds are referred to by the aforementioned abbreviation followed by the nominal molecular mass of the compound.

The aim of the current study was to investigate if arsenolipids cross the blood-brain barrier and preferentially accumulate in the brain of a higher organism. For the test samples, we chose brain and muscle tissue of skipjack tuna, Katsuwonus pelamis, because it is a top-predator marine fish naturally exposed to arsenic through its diet and surrounding environment. The analytical objectives were to extract the major arsenic species from the tuna tissues, and quantify them by using HPLC/mass spectrometry. To provide efficient and separate extraction of both lipid-and water-soluble arsenicals on the one sample, we developed a sequential extraction procedure whereby pyridine and then an aqueous ammonium bicarbonate solution were used to remove lipid-soluble and water-soluble arsenic species, respectively. The method was applied to muscle and brain tissues from five individual specimens of skipjack tuna, and the results are discussed in terms of selective accumulation of arsenolipids in the tuna brain.

\section{Experimental}

\section{Collection and sampling of tuna fish tissues}

Skipjack tuna fish (Katsuwonus pelamis) were captured by a commercial fishing vessel in the fishing area FAO 34 in the Eastern Central part of the Atlantic Ocean on September 15, 2015, and stored frozen onboard. On January 20, 2016, heads of five frozen single specimens of skipajack tuna fish (average length $67 \mathrm{~cm}$, ranging from 60 to $75 \mathrm{~cm}$ ) were retrieved for research purpose. In the laboratory, brain and muscle were dissected, tissues were carefully rinsed with distilled water before freeze-drying.

\section{Chemicals, reagents and standards}

Water $(18 \mathrm{M} \Omega \mathrm{cm}$ ) used throughout this work was from a Milli-Q Academic water purification system (Millipore $\mathrm{GmbH}$, Vienna, Austria). Ammonium bicarbonate ( $\geq 99 \%$, p.a.), pyridine ( $\geq 99 \%$ for synthesis), ammonia solution ( $\geq 25 \%$, p.a.), formic acid (FA; $\geq 98 \%$, p.a.), ammonium formate ( $\geq 95 \%$, pure), tert-butylmethylether (MTBE; $\geq 99.5 \%$, p.a.) and hydrogen peroxide $(30 \%)$ were purchased from Carl Roth GmbH + Co KG (Karlsruhe, Germany). Nitric acid (65\%, p.a.), further purified in a MLS duoPUR sub-boiling unit (MLS GmbH, Leutkirch, Germany) and methanol (HPLC grade) were purchased from VWR Chemicals International (Fontenay-sous-Bois, France). Dichloromethane (DCM; p.a.) and acetone (HPLC grade) were purchased from Chem-Lab (Zedelgem, Belgium). Glacial acetic acid (p.a.) was obtained from Merck (Darmstadt, Germany).

Single-element ICP-standard solutions of arsenic $(1000 \mathrm{mg}$ As per $\mathrm{L} \pm 2 \%$ in $2 \% \mathrm{HNO}_{3}$ ) and germanium (1000 $\mathrm{mg}$ Ge per $\mathrm{L} \pm 2 \%$ in $2 \% \mathrm{HNO}_{3}$ and $0.5 \% \mathrm{HF}$ ), both obtained from Carl Roth $\mathrm{GmbH}$ \& Co. KG (Karlsruhe, Germany), were used for the determination of total arsenic and as an internal standard, respectively. For analysis of water-soluble arsenicals, the following analytical standards were available in-house and used in this study: arsenobetaine $(\mathrm{AB}$, as the bromide salt), dimethylarsinoylacetate (DMAA), dimethylarsinoylethanol (DMAE), dimethylarsinoyl propionate (DMAP), dimethylarsinoyl butanoate (DMAB), carboxyethyl-trimethylarsonium ion (AB-2) and trimethylarsine oxide (TMAO). Dimethylarsinate (DMA) was prepared from sodium dimethylarsinate obtained from Fluka Chemie (Buchs, Switzerland). For analysis of arsenolipids, six arsenolipid standards, namely AsFA 362 (15-dimethylarsinoylpentadecanoic acid), AsFA 388 (17-dimethylarsinoyl-9heptadecenoic acid), AsFA 418 (19-dimethylarsinoylnonadecanoic acid), AsHC 332 (1-dimethylarsinoyl-pentadecane), AsHC 360 (1-dimethylarsinoyl-heptadecane), and AsHC 444 (1dimethylarsinoyl-tricosane), were available in-house, previously synthesized as described by Taleshi et $a .^{23}$

The certified reference material BCR-627 Tuna Fish Tissue purchased from Sigma Aldrich (Vienna, Austria) with a certified total As value of $4.8 \pm 0.3 \mathrm{mg}$ As per $\mathrm{kg}$ was used as quality control for total arsenic measurements and arsenic speciation analysis; in the course of this study, we obtained a value of $4.7 \pm$ $0.3 \mathrm{mg}$ As per kg (dry mass, $n=6$ ) for this reference material. In general, results are expressed on a dry mass basis. 


\section{Instrumentation}

Brain and muscle tissues were freeze-dried with a CHRIST Gamma 1-16 LSC freeze-dryer (Martin Christ GmbH, Osterode am Harz, Germany) to constant mass, and homogenized under liquid nitrogen with mortar and pestle. Microwave-assisted acid digestions were performed with a MLS Ultraclave IV microwave system (MLS, Leutkirch, Germany). Total As measurements were performed with an Agilent 7900 inductively coupled plasma mass spectrometer (ICPMS, Agilent Technologies, Waldbronn, Germany) equipped with a Scott type spray chamber and a Micro Mist concentric glass nebulizer (Glass Expansion, West Melbourne, Australia). For HPLC/ICPMS measurements of water-soluble arsenic species, an Agilent 1100 HPLC system was coupled to the Agilent 7900 ICPMS instrument. For HPLC/ICPMS measurements of lipid-soluble arsenic species, an Agilent 1260 Infinity II HPLC system was connected via a QuickSplit ${ }^{\mathrm{TM}}$ flow splitter (Analytical Scientific Instruments US) to the Agilent ICPMS 7900. For HPLC/highresolution electrospray mass spectrometry (HR ESMS) measurements, a Dionex Ultimate 3000 series instrument HPLC system (Thermo Fischer Scientific, Erlangen, Germany) was connected to a high-resolution mass spectrometer (Q-Exactive Hybrid Quadrupole-Orbitrap MS from Thermo Fischer Scientific) equipped with an electrospray ionization source. A highspeed refrigerated microcentrifuge (SCILOGEX, Rocky Hill, CT), a Hettich Hermle Z 200 A centrifuge (Andreas Hettich GmbH \& Co. KG, Tuttlingen, Germany) and a Christ RVC 233 CDplus vacuum lyophilizator (Martin Christ Gefriertrocknungsanlagen GmbH, Osterode am Harz, Germany) were used during sample preparation.

\section{Extraction of arsenic species \& purification of arsenolipids}

For method development and optimizing extraction conditions one of the five tuna brain samples was used. Pyridine was used directly and without further dilution or modification for the extraction of arsenolipids from freeze-dried tissues. Note, preliminary experiments with pyridine applied directly to wet tissue resulted in a rubbery tissue texture and poor extraction efficiency; this problem was overcome by freeze-drying the tissue before the direct application of pyridine. In general, portions of $50 \mathrm{mg}$ (brain) and $250 \mathrm{mg}$ (muscle), weighed to a precision of $0.1 \mathrm{mg}$, of homogenized and freeze-dried tissues, were placed in a $2 \mathrm{~mL}$ centrifuge tube and $15 \mathrm{~mL}$ polypropylene tube, respectively. Then, $1 \mathrm{~mL}$ (brain) and $5 \mathrm{~mL}$ (muscle) of pyridine were added for the extraction of lipid-soluble arsenic species, followed by vortexing, and shaking the mixture for $1 \mathrm{~h}$ on a mechanical rotation device. Afterwards, the mixtures were centrifuged for $15 \mathrm{~min}$ at $21000 \times g$ (brain) and $4000 \times g$ (muscle) and the supernatants were removed and further purified by normal-phase solid-phase-extraction (SPE) for subsequent analysis of arsenolipids. For the extraction of watersoluble arsenic species from tissues, $1 \mathrm{~mL}$ (brain) and $5 \mathrm{~mL}$ (muscle) of an aqueous $20 \mathrm{mM}$ ammonium bicarbonate solution $\mathrm{pH} 9.2$ ( $\mathrm{pH}$ adjusted with aqueous ammonia) were added to the remaining pellet. After vortexing and shaking $(1 \mathrm{~h})$, the mixtures were centrifuged as described above. The supernatants were decanted and filtered through $0.2 \mu \mathrm{m}$ Nylon $^{\mathrm{TM}}$ syringe filters prior to analysis.

For DCM/MeOH and methyl-tert-butylether (MTBE)/MeOH extractions, $1 \mathrm{~mL}$ mixtures of DCM/MeOH $(2: 1, \mathrm{v} / \mathrm{v})$ or MTBE/ $\mathrm{MeOH}(10: 3, \mathrm{v} / \mathrm{v})$ were added to portions of $50 \mathrm{mg}$ freeze-dried brain tissue material and mixtures were shaken for $1 \mathrm{~h}$. After centrifugation, the supernatant was decanted and the remaining pellet was dried under vacuum. Then, $1 \mathrm{~mL}$ of an aqueous $20 \mathrm{mM}$ ammonium bicarbonate solution pH 9.2 was added to the pellet, vortexed and shaken for $1 \mathrm{~h}$ to extract water-soluble arsenicals.

Pyridine, DCM/MeOH, MTBE/MeOH and aqueous crude extracts were analysed without any further treatment by HPLC/ MS. Additionally, arsenolipids were purified from pyridine extracts of brain and muscle tissues according a SPE-silica clean-up procedure developed for the purification of arsenolipids from algae. ${ }^{16}$ The pyridine extracts of brain $(0.5 \mathrm{~mL})$ and muscle tissues $(4 \mathrm{~mL})$ were evaporated to dryness and the residues were redissolved in $1 \mathrm{~mL}$ of DCM/acetone $(1: 1, \mathrm{v} / \mathrm{v}) /$ $1 \% \mathrm{v} / \mathrm{v}$ FA. The crude extracts were transferred quantitatively to a small silica column $(230 \times 5 \mathrm{~mm}$ glass Pasteur pipette plugged with cotton wool and filled with silica to a height of $6 \mathrm{~cm}$ ) that was conditioned with $5 \mathrm{~mL}$ of DCM/acetone $(1: 1, \mathrm{v} / \mathrm{v}) / 1 \%$ $(\mathrm{v} / \mathrm{v})$ FA. Then, the column was washed with $5 \mathrm{~mL}$ of DCM/ acetone $(1: 1, \mathrm{v} / \mathrm{v}) / 1 \%(\mathrm{v} / \mathrm{v})$ FA and $5 \mathrm{~mL}$ of methanol before eluting arsenolipids with $1 \times 10 \mathrm{~mL}$ of methanol/1\% (v/v) $\mathrm{NH}_{3}$. This fraction was evaporated to dryness and redissolved in $0.5 \mathrm{~mL}$ of methanol for arsenolipid analysis.

At each step of the extraction and purification procedures, varying portions of extracts, pellets and fractions were subjected to a microwave-assisted acid digestion followed by determination of the arsenic concentrations in digested samples by ICPMS.

\section{Determination of the total arsenic content}

Portions of $50 \mathrm{mg}$ (weighed to a precision of $0.1 \mathrm{mg}$ ) of homogenized and freeze-dried brain \& muscle tissues and certified reference material were placed in $12 \mathrm{~mL}$ quartz tubes of the digestion system. Then $2 \mathrm{~mL}$ of nitric acid and $1 \mathrm{~mL}$ of an internal standard solution containing $100 \mu \mathrm{g} \mathrm{L} \mathrm{L}^{-1}$ of Ge in $1 \%$ (v/ v) $\mathrm{HNO}_{3}$ were added. The tubes were covered with Teflon caps, placed in a Teflon rack, and transferred to the microwave system; an argon pressure of $4 \times 10^{6} \mathrm{~Pa}$ was applied, and the acid mixture was heated to $250{ }^{\circ} \mathrm{C}$ for $30 \mathrm{~min}$. After mineralization and cooling to room temperature, the digested samples were transferred to $15 \mathrm{~mL}$ polypropylene tubes and diluted with water to $10 \mathrm{~mL}$. The digested samples were then analyzed for total As concentration by ICPMS.

Determinations of total As were made by using ICPMS with conventional nebulization and operated with helium (4.0 $\mathrm{mL} \mathrm{min}^{-1}$ ) as collision cell gas for removing polyatomic interferences from argon chloride $\left({ }^{40} \mathrm{Ar}^{35} \mathrm{Cl}\right.$ on $\left.{ }^{75} \mathrm{As}\right)$. Monitored masses were $m / z 75\left({ }^{75} \mathrm{As}, 0.3 \mathrm{~s}\right.$ per point), and $\mathrm{m} / \mathrm{z} 72$ and 74 (internal standard ${ }^{72} \mathrm{Ge}$ and ${ }^{74} \mathrm{Ge}$ (each $0.1 \mathrm{~s}$ per point)). Standards for calibration were prepared in $15 \mathrm{~mL}$ polypropylene tubes (Greiner Bio-One International $\mathrm{GmbH}$, Kremsmünster Austria) containing $20 \%(\mathrm{v} / \mathrm{v}) \mathrm{HNO}_{3}$ for matrix matching and 
the internal Ge standard at a final concentration of $10 \mu \mathrm{g} \mathrm{L}^{-1}$; calibration range was 0.1 to $100 \mu \mathrm{g}$ As per L. Each sample was analyzed 2-4 times for total As, and SDs of measured arsenic values were always $<10 \%$.

\section{Analysis of arsenic species in tissue extracts by HPLC/mass spectrometry}

Water-soluble arsenic species in aqueous extracts (acidified with $20 \% \mathrm{v} / \mathrm{v}$ FA) were investigated by HPLC/ICPMS under cation-exchange HPLC conditions. An Agilent Ionosphere 5C $(200 \times 3 \mathrm{~mm} ; 5 \mu \mathrm{m})$ cation-exchange column with $20 \mathrm{mM}$ ammonium formate $\mathrm{pH} 2.60$ (pH adjusted with formic acid) containing $10 \% \mathrm{v} / \mathrm{v}$ methanol as mobile phase under isocratic elution conditions was used. The ICPMS was operated in no gas mode using $1 \% \mathrm{CO}_{2}$ in argon as optional gas to enhance the arsenic signal. Monitored masses in time resolved analysis mode (one channel per isotope) were $m / z 75$ (0.3 s per point for ${ }^{75} \mathrm{As}$ ), $\mathrm{m} / z 53$ (0.05 s per point, ${ }^{40} \mathrm{Ar}^{13} \mathrm{C}$ to monitor carbon), $\mathrm{m} / \mathrm{z}$ 77 and $m / z 82$ (each $0.1 \mathrm{~s}$, to ascertain possible argon chloride interferences on ${ }^{75} \mathrm{As}$ ). Quantification of water-soluble arsenic species using cation-exchange HPLC was based on external calibration against the standards DMA, AB and TMAO in the calibration range 1-200 $\mu \mathrm{g}$ As per L.

Arsenolipids in crude and purified pyridine extracts were separated using the ACE Ultra Core 5 SuperPhenylHexyl Column $(250 \times 4.6 \mathrm{~mm} ; 5 \mu \mathrm{m})$ employing gradient elution with mobile phases comprising mixtures of $25 \mathrm{mM}$ aqueous ammonium acetate $\mathrm{pH} 9.2$ and methanol (for chromatographic details see legend of Fig. 3 and 4 ). 10\% of the column effluent was directed post-column to the ICPMS in the HPLC/ICPMS setup used for arsenic selective detection and quantification of arsenolipids. The flow to the ICPMS was supported with an aqueous make-up flow ( $\left.0.8 \mathrm{~mL} \mathrm{~min}^{-1}\right)$ containing $20 \mu \mathrm{g}$ Ge per $\mathrm{L}$ as internal standard and $0.1 \%(\mathrm{v} / \mathrm{v})$ FA provided from an isocratic pump to ensure stable plasma conditions. To maintain a constant carbon load to the plasma, a carbon compensation solution containing $5 \%(\mathrm{v} / \mathrm{v})$ acetone/water was introduced with the peristaltic pump of the ICPMS to the spray chamber. ${ }^{24}$ The ICPMS instrument was operated in no gas mode and timeresolved analysis mode using sample and skimmer cones made of platinum. Monitored masses were $m / z 53$ (0.01 s per point), $m / z 74$ (0.01 s per point), $m / z 75$ (0.3 s per point), $m / z 77$ and $m / z 82$ ( $0.3 \mathrm{~s}$ per point). Mixed calibration standards of three arsenic fatty acids (AsFA 362, AsFA 388, and AsFA 418) and three arsenic hydrocarbons (AsHC 332, AsHC 360, and AsHC 444) were prepared in methanol in the calibration range of 10$200 \mu \mathrm{g}$ of As per L; quantification was based on peak areas.

For HPLC/HR ESMS measurements of arsenic species in tissue extracts, the same chromatographic conditions that were applied in HPLC/ICPMS measurements (see legends to Fig. 2-4) were used. The high-resolution mass spectrometer was operated in positive mode with nitrogen as the drying gas $\left(450{ }^{\circ} \mathrm{C}\right)$,

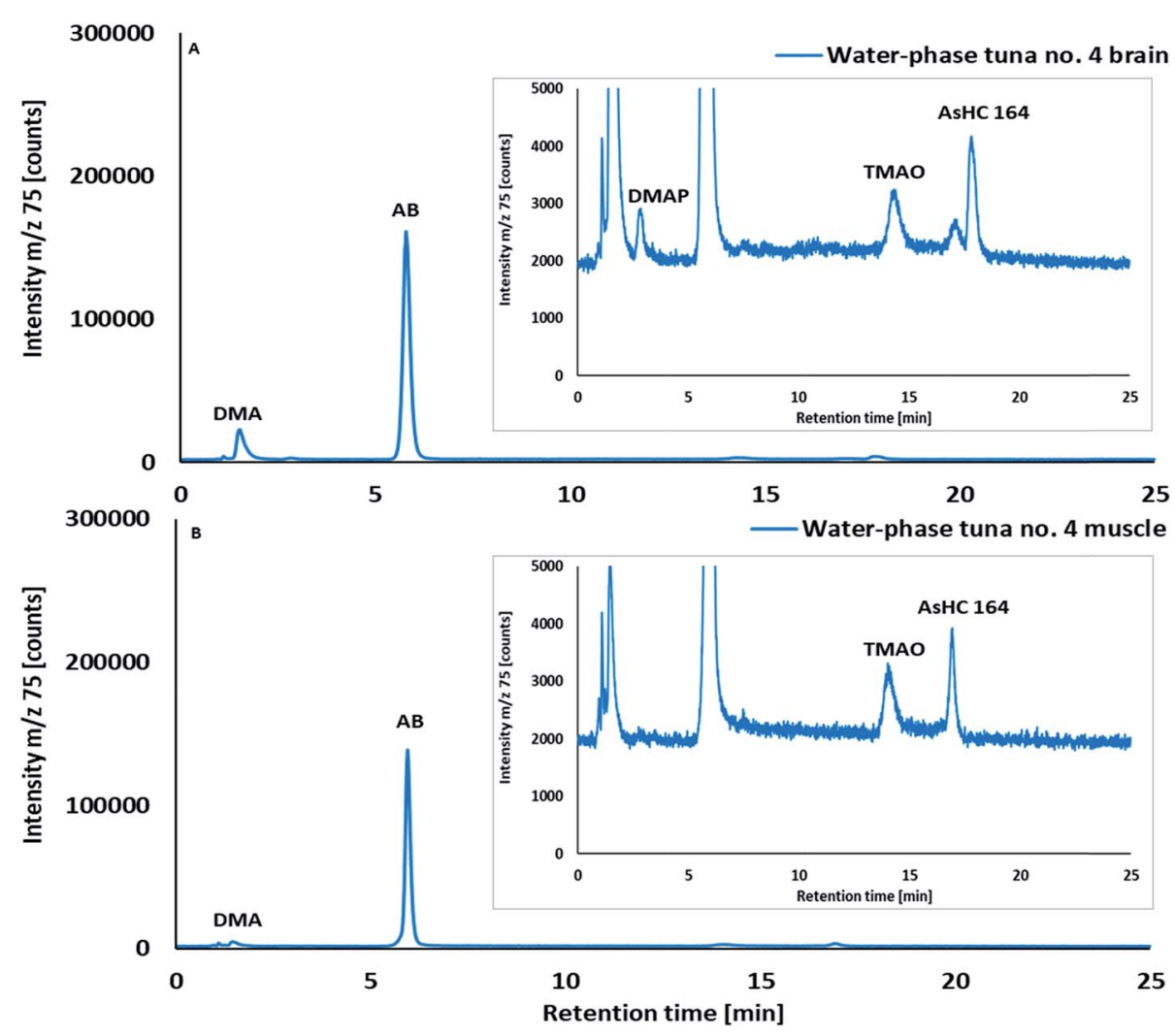

Fig. 2 Cation-exchange HPLC/ICPMS chromatograms of crude water extracts of (A) brain and (B) muscle tissues of skipjack tuna no. 4. Column, Varian lonosphere $5 \mathrm{C}(100 \times 3 \mathrm{~mm} ; 5 \mu \mathrm{m})$; mobile phase, $20 \mathrm{mM}$ ammonium formate $\mathrm{pH} 2.60$ containing 10\% (v/v) methanol; flow rate, 1 $\mathrm{mL} \mathrm{min}^{-1}$ and injection volume, $20 \mu \mathrm{L}$. 


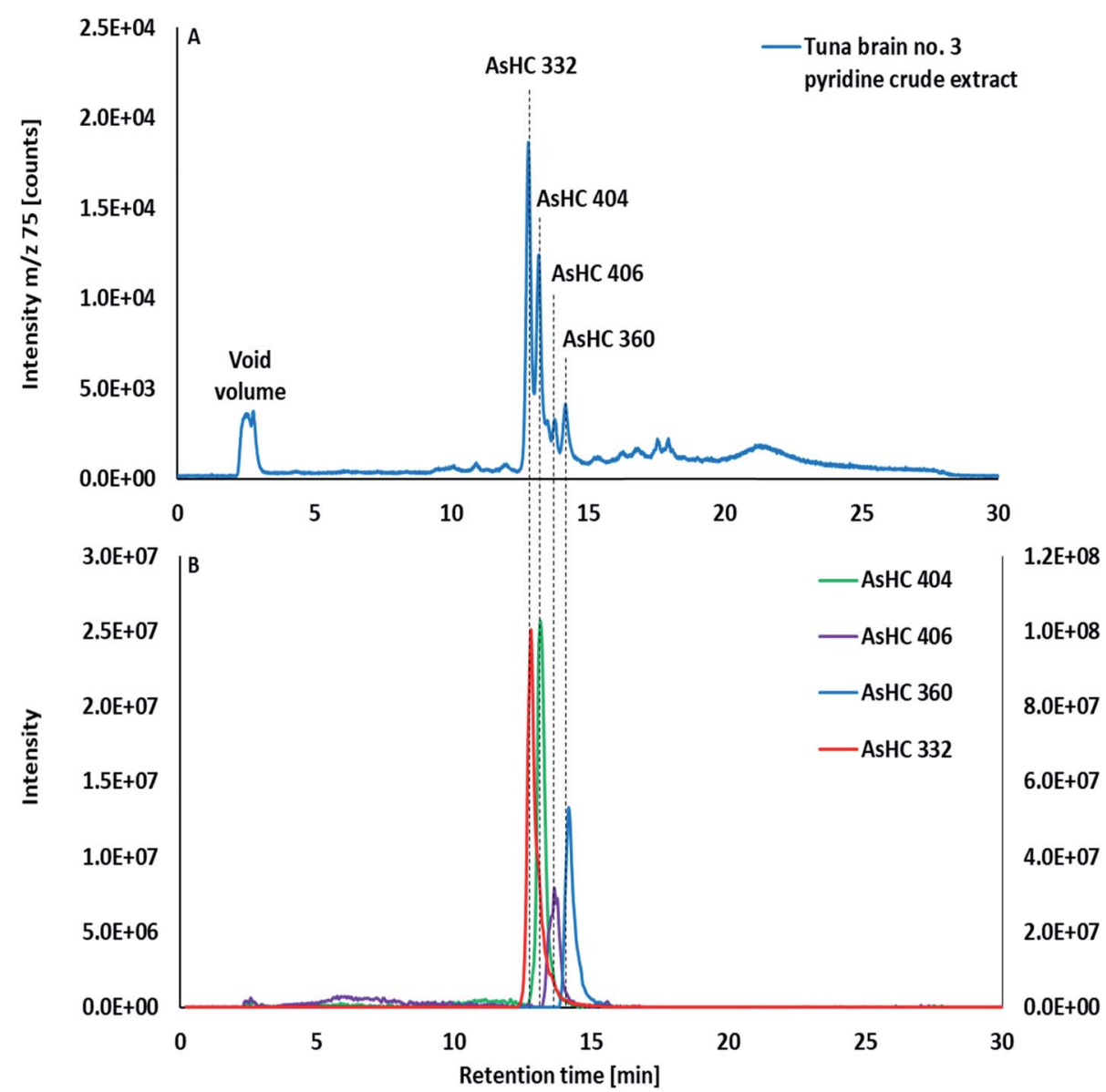

Fig. 3 HPLC/ICPMS chromatogram (A) and HPLC/HR ESMS extracted ion chromatograms (B) of identified arsenolipids isolated with a mass tolerance of $\Delta 5 \mathrm{ppm}$ of a pyridine crude extract of tuna fish no. 3. Column, ACE Ultra Core 5 SuperPhenylHexyl $(250 \times 4.6 \mathrm{~mm} ; 5 \mu \mathrm{m}) ; \mathrm{mobile}$ phases, $25 \mathrm{mM} \mathrm{NH}_{4}\left(\mathrm{CH}_{3} \mathrm{COO}\right) /$ water $\mathrm{pH} 9.2$ ( $\mathrm{pH}$ adjusted with aqueous ammonia) and $25 \mathrm{mM} \mathrm{NH}_{4}\left(\mathrm{CH}_{3} \mathrm{COO}\right) / \mathrm{MeOH}$ pH 9.2; gradient elution: 0-15 min from $60-100 \%, 15-25$ min holding at $100 \%$, and returning at 25.1 min to $60 \% 25 \mathrm{mM} \mathrm{NH}_{4}\left(\mathrm{CH}_{3} \mathrm{COO}\right) / \mathrm{MeOH}_{\mathrm{pH}} 9.2 ;$ flow rate, 1 $\mathrm{mL} \min ^{-1} ; \mathrm{T}, 40{ }^{\circ} \mathrm{C}$ and injection volume $20 \mu \mathrm{L}$. The retention time shift (ca $0.2 \mathrm{~min}$ ) between HPLC/ICPMS and HPLC/HR ESMS measurements was normalized by comparison of authentic arsenolipid standards and the HR ESMS chromatogram was adjusted accordingly. The extracted ion chromatogram of AsHC 332 is displayed on the secondary axis.

a capillary voltage of $3500 \mathrm{~V}$, and a capillary temperature of $300{ }^{\circ} \mathrm{C}$. The following instrumental settings were used for the assessment of arsenic species in tissue extracts: full scan at a resolution of 70000 full width at half-maximum (fwhm) within a scan range of $\mathrm{m} / \mathrm{z} 100-1500$, with automatic gain control (AGC) target set to $3 \times 10^{6}$, and a maximal injection time of $100 \mathrm{~ms}$. The following settings were used for the datadependent MS/MS measurements: isolation window set to $\mathrm{m} / \mathrm{z}$ 0.4, resolution of $17500 \mathrm{fwhm}$, and AGC target set to $1 \times 10^{6}$. A maximal injection time of $200 \mathrm{~ms}$ and a loop count of 5 were used. The intensity threshold was set to $4 \times 10^{4}$, and normalized collision energies of 15,35 or $50 \mathrm{eV}$ were used.

\section{Results and discussion}

Extraction of arsenic species

For analyzing both water- and lipid-soluble arsenic species in tissue samples, we developed a method for the selective extraction of arsenolipids and water-soluble arsenic species from the same sample. Normal lipids are commonly extracted from solid materials using mixtures of chloroform $/ \mathrm{MeOH},{ }^{25,26}$ and more recently $\mathrm{MTBE} / \mathrm{MeOH}^{27}$ for improved practical sample handling. Current arsenolipid research employs a mixture of $\mathrm{DCM} / \mathrm{MeOH}$ for the extraction of most common arsenolipids from solid samples. ${ }^{24}$ However, under these conditions considerable amounts of water-soluble arsenic species are also extracted, which complicates their targeted analysis from the same sample. Water-soluble arsenic species that are extracted into the organic phase can be investigated after the addition of water by analyzing the aqueous phase. This partitioning step, however, presents practical difficulties in sample handling, and, additionally, the presence of water introduces the possibility of degrading the arsenolipids. Degradation of labile non-polar arsenolipids, likely through hydrolysis, has been observed in fish meal samples when water was used as a first extractant before subsequent extraction of arsenolipids with organic solvents. ${ }^{28}$

Consequently, our extraction strategy was to search for a mild organic solvent with polarity similar to that of a DCM/ $\mathrm{MeOH}$ mixture, which would efficiently extract arsenolipids, 

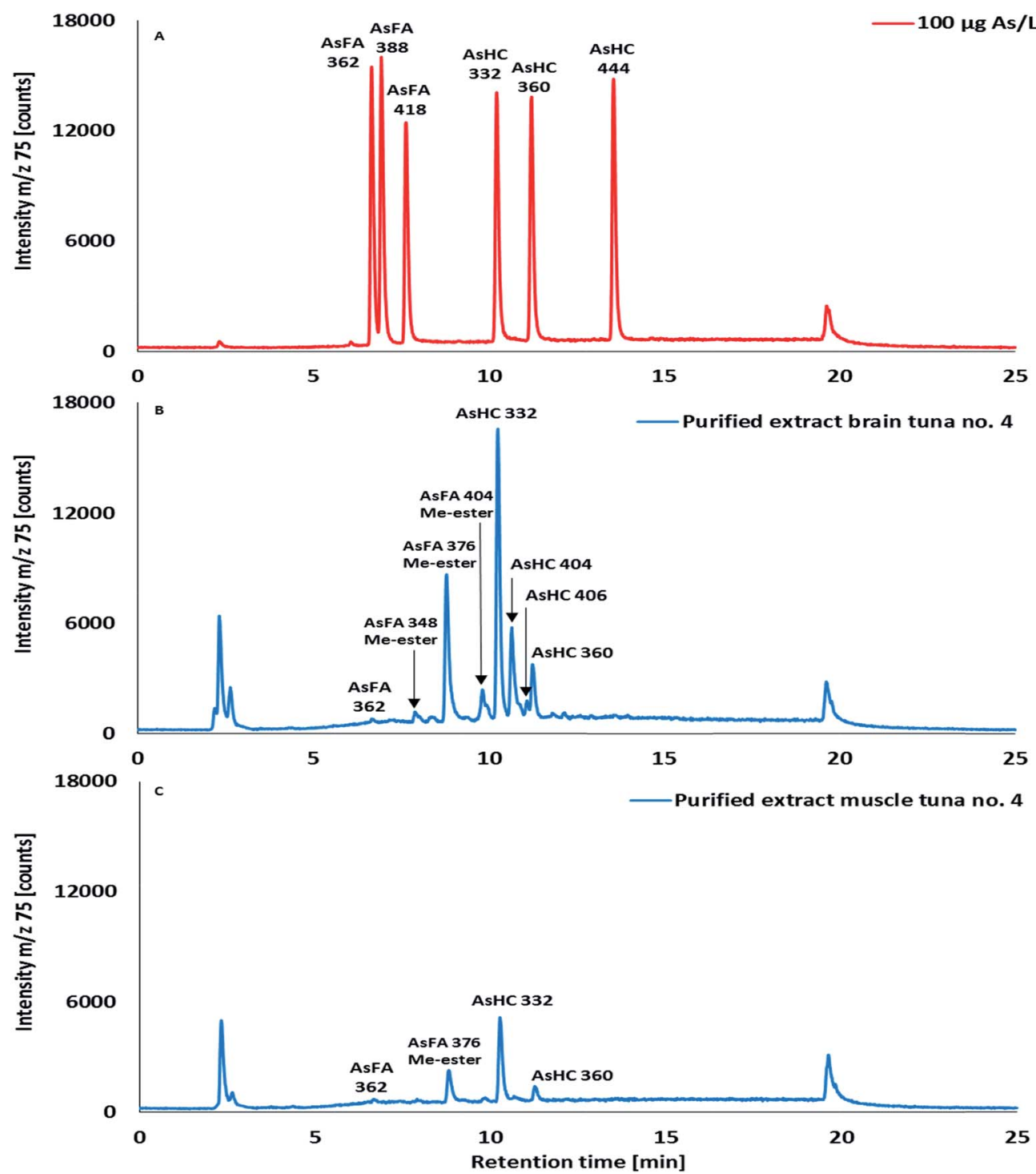

Fig. 4 HPLC/ICPMS chromatograms of (A) an arsenolipid mixed standard solution of AsFA 362, AsFA 388, AsFA 418, AsHC 332, AsHC 360 and AsHC 444 (each $100 \mu \mathrm{g}$ As per L), and purified pyridine extracts of (B) brain and (C) muscle of skipjack tuna no. 4. Column, ACE Ultra Core 5 SuperPhenylHexyl $(250 \times 4.6 \mathrm{~mm} ; 5 \mu \mathrm{m})$; mobile phases, $25 \mathrm{mM} \mathrm{NH}_{4}\left(\mathrm{CH}_{3} \mathrm{COO}\right) /$ water $\mathrm{pH} 9.2$ ( $\mathrm{pH}$ adjusted with aqueous ammonia) and $25 \mathrm{mM}$ $\mathrm{NH}_{4}\left(\mathrm{CH}_{3} \mathrm{COO}\right) / \mathrm{MeOH}$ pH 9.2; gradient elution: 0-2 min from 0-20\%, 2-4 min from 20-80\%, 4-12 min from 80-100\%, 12-17 min holding at $100 \%$ and returning at $17.1 \mathrm{~min}$ to $25 \mathrm{~min}$ to $0 \% 25 \mathrm{mM} \mathrm{NH}_{4}\left(\mathrm{CH}_{3} \mathrm{COO}\right) / \mathrm{MeOH} \mathrm{pH} \mathrm{9.2;} \mathrm{flow} \mathrm{rate,} 1 \mathrm{~mL} \mathrm{~min}^{-1} ; T^{\circ} 40^{\circ} \mathrm{C}$ and injection volume $20 \mu \mathrm{L}$.

but only negligible amounts of water-soluble arsenic species. In this way we could avoid the use of water in a partitioning step, and hence prevent possible hydrolysis of the arsenolipids. Based on the relative polarities of DCM (0.42) and $\mathrm{MeOH}(0.95)$ retrieved from elutropic series tables, ${ }^{29}$ a $2: 1(\mathrm{v} / \mathrm{v})$ mixture of $\mathrm{DCM} / \mathrm{MeOH}$ shows a calculated relative polarity of 0.61 . Pyridine with a relative polarity of 0.71 resides in a similar polarity range than that of a $\mathrm{DCM} / \mathrm{MeOH}$ mixture, however, is slightly more polar. Latter aspect could benefit the extraction of arsenolipids because of their polar dimethylarsinoyl-group, characteristic for nearly all arsenolipids identified so far, which facilitates the solubility in polar solvents.

Therefore, we explored a sequential extraction on the same tissue sample using pyridine for selective removal of arsenolipids, and then an aqueous ammonium bicarbonate solution to remove water-soluble arsenic species. DCM/MeOH and $\mathrm{MTBE} / \mathrm{MeOH}$ methodologies for extracting lipids were used as reference extraction methods. The mass balance of the reference and pyridine extraction methods applied on a fish brain tissue sample is shown in Table 1.

With our pyridine extraction method, around $60 \%$ and $30 \%$ of the total As in the fish brain was extractable with pyridine and aqueous ammonium bicarbonate, respectively. Relative to the data for pyridine, higher amounts of arsenic (74-83\%) were extracted into the organic phases of $\mathrm{DCM} / \mathrm{MeOH}$ and MTBE/ $\mathrm{MeOH}$, whereas lower amounts (3-18\%) were removed in the subsequent extraction with aqueous ammonium bicarbonate (Table 1). These results suggested that considerable amounts of 
water-soluble As compounds had been extracted into the $\mathrm{DCM} / \mathrm{MeOH}$ and $\mathrm{MTBE} / \mathrm{MeOH}$ phases. This interpretation was supported by analysis of $\mathrm{DCM} / \mathrm{MeOH}$ and $\mathrm{MTBE} / \mathrm{MeOH}$ extracts by reversed-phase HPLC/ICPMS (ESI Fig. S1†), which showed elevated concentrations of non-retained arsenic corresponding to $12-25 \%$ of the total As content, assumed to be mostly water-soluble, eluting in the void volume. However, it cannot be excluded that water-soluble degradation products of labile arsenolipids are formed under these extraction conditions that contribute to the arsenic in the void volume. In contrast, less than $5 \%$ of the total arsenic was found in the void volume of pyridine extracts indicating that pyridine hardly extracts the watersoluble arsenic compounds and prevents at the same time the hydrolysis of labile arsenolipids (Table 1 and Fig. 3). Storage of in-house available previously synthesized arsenolipid standards, ${ }^{23}$ namely the AsHCs 332,360 and 444, 360 and AsFAs 362, 388 and 418, in pyridine over a one-week period at room temperature and subsequent analysis by HPLC/ICPMS showed no degradation/transformation of these compounds. Crude extracts obtained after the extraction with pyridine were analyzed within two days after extraction. Therefore, we do not expect a degradation/ transformation of arsenolipids present in these extracts during the extraction process and storage until analysis, however a hydrolysis of labile arsenolipids beyond storing time cannot be excluded.

Arsenobetaine was identified as the major water-soluble arsenical in the tuna samples, while DMA was present as a minor arsenic species (see ESI Fig. S2 and S3†े). Arsenobetaine and DMA could not be reliably quantified with the DCM/MeOH and MTBE/MeOH extraction methods (Table 1). The sequential extraction with pyridine and aqueous ammonium bicarbonate, however, selectively extracted arsenobetaine and other water-soluble arsenicals such as DMA, into the aqueous layer, rather than into the pyridine, producing excellent quantitative results as shown by the analysis of CRM BCR-627 Tuna fish tissue, which has been included in our study for quality control, but was also investigated as a potential future seafood reference material for arsenolipids (ESI Fig. S4 and Table S1 $\dagger$ ). When applying our pyridine method $(n=3)$ on this fish tissue material, $10 \pm$ $1 \%$ of its total As were found in the organic phase, $74 \pm 1 \%$ in water phase and $16 \pm 1 \%$ remained in the pellet; the recovery of the sum of all three phases based on the total As was $107 \pm$ $2 \%$. In terms of arsenic species, this CRM has certified values of $3.90 \pm 0.22 \mathrm{mg}$ As per $\mathrm{kg}$ and $0.150 \pm 0.022 \mathrm{mg}$ As per $\mathrm{kg}$ for $\mathrm{AB}$ and DMA, respectively; we obtained $3.66 \pm 0.07 \mathrm{mg}$ As per $\mathrm{kg}(n=3)$ for $\mathrm{AB}$ and $0.15 \pm 0.02 \mathrm{mg}$ As per $\mathrm{kg}(n=3)$ for DMA corresponding to recoveries of $94 \pm 2 \%(n=3)$ and 100 $\pm 15 \%(n=3)$, respectively.

The total mass extracted from the brain was very similar for all three organic extracts ( $66 \pm 3 \%$; mean of all extractions $n=9$ ). Analysis of the same extracts by HPLC/ICPMS (ESI Fig. S1 $\dagger$ ) showed that the amounts of arsenolipids extracted from brain samples with the pyridine were comparable to those obtained with the other two solvents. The arsenolipids 
AsHC 332 and AsHC 360 were used as markers to compare the extraction efficiency of the three methods; our pyridine extraction method returned results for these two compounds within $8 \%$ of those obtained with $\mathrm{DCM} / \mathrm{MeOH}$ and $\mathrm{MTBE} / \mathrm{MeOH}$ extractions (Table 1).

Thus, pyridine was able to efficiently and selectively extract arsenolipids from the tuna brain tissue while essentially leaving behind the water-soluble arsenicals, which could then be extracted by the aqueous bicarbonate solution. This selectivity enabled the parallel investigation of both arsenolipids and water-soluble arsenic species in the same sample. The method was then used to investigate the arsenic species in brain and muscle tissues of tuna fish.

\section{Total arsenic concentrations in the brain and muscle of skipjack tuna}

The total arsenic content in the muscle tissues of five specimens of tuna ranged from 4.0 to $5.8 \mathrm{mg}$ As per $\mathrm{kg}$ with a mean total arsenic concentration of $4.7 \pm 0.8 \mathrm{mg}$ As per $\mathrm{kg}(n=5)$, respectively. These arsenic concentrations are similar to those reported for muscle tissues of various tuna species ${ }^{30,31}$ and in canned tuna, ${ }^{32}$ and are in accordance with arsenic concentrations commonly found in muscle tissue of marine fish. The total arsenic content in brain tissues of skipjack tuna, however, showed up to three-fold higher concentrations than in the muscle tissues of the same specimen, ranging from 9.1 to $17.4 \mathrm{mg}$ As per $\mathrm{kg}$ with mean and median values of 12.2 and $10.9 \mathrm{mg}$ As per $\mathrm{kg}(n=5)$, respectively, suggesting an accumulation of arsenic in the brain of this marine fish (Table 2 and ESI Fig. S5†).

Most of the arsenic in the brain was extractable with pyridine (6.2-8.7 $\mathrm{mg}$ As per $\mathrm{kg}$ corresponding to $52-58 \%$ ), whereas around $30 \%$ of the total arsenic was found in the water phase and around $15 \%$ remained in the pellet (Table 2). For the muscle tissue, only $20 \%$ (mean, $n=5$; range $11-30 \%$ ), was extractable with pyridine, whereas $55 \%$ (mean, $n=5$; range 41$66 \%$ ) of the total arsenic was found in the water phase.

\section{Water-soluble As species in the brain and muscle of skipjack tuna}

Water-soluble arsenic species in aqueous extracts of brain and muscle tissues of skipjack tuna were investigated by HPLC/ ICPMS (Fig. 2) and HPLC/HR ESMS (ESI, Fig. S2 and S3; Table $\mathrm{S} 2 \dagger)$. Arsenobetaine, the major water-soluble arsenical in muscle tissues of marine fish, crustaceans and mollusks, ${ }^{33,34}$ was also the major water-soluble arsenic species in both muscle tissues (mean $47 \%$ of total As; range $31-57 \%$ ) and brain tissues (mean $24 \%$ of total As, $15-31 \% ; n=5$ ) of skipjack tuna. DMA, a common arsenic metabolite of inorganic arsenic, ${ }^{35}$ arsenosugars and arsenolipids, ${ }^{36}$ and TMAO were detected as minor constituents in both brain and muscle tissues, whereas a trace amount of DMAP, a small dimethylarsinoyl carboxylic acid and metabolite of arsenolipids, ${ }^{37,38}$ was detected only in the brain (Fig. 2, ESI Fig. S2, S6 and Table S2 $\dagger$ ). DMAB, an urinary metabolite observed after ingestion of arsenolipids ${ }^{37,38}$ and structurally similar to DMAP, was not detected. 
In addition to the known water-soluble arsenicals described above, a late eluting arsenic peak (Fig. 1, retention time (RT) = ca $17 \mathrm{~min}$ ) in the aqueous extracts was observed by cationexchange HPLC/ICPMS. Analysis by HPLC/HR ESMS showed that this As species had a molecular mass of $m / z 164.0177$ (ESI, Fig. S2 and S3; Table S2 $\dagger$ ), which suggested it was a short chain arsenic-containing hydrocarbon with a molecular formula of $\mathrm{C}_{5} \mathrm{H}_{13} \mathrm{AsO}$; we could, however, not confirm its structure.

\section{Lipid soluble arsenic species in the brain and muscle of tuna}

Investigation of the arsenolipids in the pyridine crude extracts of brain tissues by HPLC/ICPMS revealed the presence of appreciable quantities of two AsHCs, namely AsHC 332 and AsHC 360, together with traces of AsFA 362; these compounds were identified by co-chromatography with authentic arsenolipid standards (Fig. 3; ESI, Fig. S1 and S7†).

Moreover, traces of arsenicals with retention times resembling those of medium chain AsFAs, a strong arsenic signal around 11-13 min, minor amounts of late eluting compounds (around $15 \mathrm{~min}$ ) together with a broad arsenic peak between 1824 min (Fig. 3 and ESI Fig. S1D and S7B-F†) were observed in brain crude extracts under reversed-phase HPLC conditions. The identity of AsFA 362, AsHC 332 and AsHC 360 in brain crude extracts was confirmed by HPLC/high resolution mass spectrometry and accurate mass measurements in positive ionization mode of protonated molecular ions (full MS). The fragment ions $\mathrm{m} / z 104.96799$ and $\mathrm{m} / \mathrm{z} 122.97855$ characteristic for arsenolipids containing a dimethylarsinoyl moiety were observed in $\mathrm{MS}^{2}$ spectra of AsHC 332 and AsHC 360, whereas the intensity of the $[\mathrm{M}+\mathrm{H}]^{+}$ion of AsFA 362 was below the threshold required for being selected in a MS/MS experiment. Additionally, accurate masses of $[\mathrm{M}+\mathrm{H}]^{+}$ions of two more AsHCs, AsHC 404 and AsHC 406, were identified after selectively extracting the fragment ions $\mathrm{m} / \mathrm{z} 104.96799$ and $\mathrm{m} / \mathrm{z} 122.97855$ from the obtained MS spectra. In a previous study, ${ }^{2}$ the arsenolipids AsFA 362, AsHC 332, AsHC 360 and AsHC 404 have also been identified in muscle tissue of sashimi tuna. The arsenic peak at RT $4.6 \mathrm{~min}$ and the compounds eluting after $12.5 \mathrm{~min}$ did not show any of these fragment ions (ESI Fig. S7 B-F $\dagger$ ). Their low concentrations and the high matrix load of pyridine crude extracts $(>50 \%$ of the total brain mass was extractable with pyridine), challenged the identification of these compounds. HPLC analysis of crude extracts showed no practical difficulties. However, a higher arsenic background and poor peak shapes, which negatively influenced chromatographic separation have been observed (ESI S7 $\dagger$ ).

To better elucidate the structure of the unidentified arsenolipids and to improve HPLC separation, we applied a SPE-silica clean-up previously used for purifying arsenolipids from algae $\mathbf{1 0}^{\mathbf{1 0 , 1 6 , 2 4}}$ on the pyridine crude extracts of five tuna brain and muscle samples. For example, applying this clean-up procedure to the pyridine crude extract $(0.5 \mathrm{~mL})$ of tuna brain sample no. 1 containing $199 \mathrm{ng}$ As in $18 \mathrm{mg}$ of total mass returned a purified arsenic fraction $\left(1 \% \mathrm{NH}_{3}(\mathrm{v} / \mathrm{v}) /\right.$ methanol) containing $173 \mathrm{ng}$ As in just $3 \mathrm{mg}$ of total mass. Under these conditions, $87 \%$ of the arsenic loaded onto the column was recovered in the ammonia methanol fraction, whereas $>80 \%$ of the total mass was removed. The total recovery of arsenic loaded onto the silica column was $97 \%$ in this sample. The rest of the samples closely matched those values with $\mathrm{SD}<5 \%$. Application of the clean-up procedure to pyridine muscle tissue extracts returned similar results to those obtained with brain samples, however, the arsenic content in the purified fraction was slightly lower, around $70 \%$, with $90 \%$ of the total arsenic loaded onto the column recovered within all collected fractions. The purified fractions were analysed by HPLC/ICPMS (Fig. 4 and ESI Fig. S8 and S9†) and HPLC/HR ESMS.

Purification of pyridine brain extracts significantly improved the HPLC separation as indicated by a lower arsenic background, and sharper and better-resolved peaks in HPLC/ICPMS measurements. However, changes in the arsenic profile of silica-purified extracts compared to crude extracts were observed after the purification procedure when analysed by HPLC/ICPMS (ESI Fig. S10 $\dagger$ ). The identity of arsenic fatty acid AsFA 362, and the four AsHCs 332, 360, 404 and 406, detected in brain crude extracts (Table 3 ) remained unchanged in purified extracts. It was noticeable, however, that an arsenic signal overlapping with AsHC 404 within the band of unresolved peaks (RT 10-12 $\mathrm{min}$ ) and the late eluting arsenicals (>12 min) detected in crude extracts disappeared after the silica clean-up. Instead, several new arsenic species appeared in the purified

Table 3 Arsenolipids in purified brain and muscle tissue extracts of skipjack tuna identified by HPLC/HR ESMS in positive ionization mode and quantified by HPLC/ICPMS. Percentage of total arsenic given as mean of $n=5$, followed by the range of percentage values ${ }^{a}$

\begin{tabular}{|c|c|c|c|c|c|c|}
\hline Compound code & Formula $[\mathrm{M}+\mathrm{H}]^{+}$ & Mass theor. & Mass exp. & $\Delta m[\mathrm{ppm}]$ & Brain* (\% of total As) & Muscle* (\% of total As) \\
\hline AsFA 362 & $\mathrm{C}_{17} \mathrm{H}_{36} \mathrm{AsO}_{3}$ & 363.1875 & 363.1883 & 2.2 & $0.6(0.2-0.7)$ & $0.09(0.04-0.1)$ \\
\hline AsHC 332 & $\mathrm{C}_{17} \mathrm{H}_{38} \mathrm{AsO}$ & 333.2133 & 333.2130 & -0.8 & $14(11-19)$ & $1.4(1.0-2.4)$ \\
\hline AsHC 360 & $\mathrm{C}_{19} \mathrm{H}_{42} \mathrm{AsO}$ & 361.2446 & 361.2446 & $<0.1$ & $3(2.1-3.4)$ & $0.3(0.2-0.5)$ \\
\hline AsHC 404 & $\mathrm{C}_{23} \mathrm{H}_{38} \mathrm{AsO}$ & 405.2133 & 405.2132 & -0.3 & $6(4.7-6.9)$ & $0.08(0.04-0.11)$ \\
\hline AsHC 406 & $\mathrm{C}_{23} \mathrm{H}_{40} \mathrm{AsO}$ & 407.2290 & 407.2279 & -2.6 & $1(0.7-1.2)$ & $<0.01(\mathrm{LOD})$ \\
\hline AsFA 348 Me-ester & $\mathrm{C}_{16} \mathrm{H}_{34} \mathrm{AsO}_{3}$ & 349.1718 & 349.1720 & 0.5 & $0.6(0.3-1.0)$ & $0.05(0.04-0.08)$ \\
\hline AsFA 376 Me-ester & $\mathrm{C}_{18} \mathrm{H}_{38} \mathrm{AsO}_{3}$ & 377.2031 & 377.2023 & -2.1 & $7(3.8-11)$ & $0.8(0.5-1.3)$ \\
\hline AsFA 404 Me-ester & $\mathrm{C}_{20} \mathrm{H}_{42} \mathrm{AsO}_{3}$ & 405.2344 & 405.2340 & -1.1 & $1.7(1.0-2.1)$ & $0.1(0.07-0.14)$ \\
\hline Total As [mg As per $\mathrm{kg}$ ] & & & & & $12.2(9.1-17.4)$ & $4.4(4.0-5.8)$ \\
\hline
\end{tabular}


extracts including a strong arsenic signal at RT 8.8 min eluting in a retention time window between AsFA 362 and AsHC 332 (Fig. 4B). Investigation of these compounds by HPLC/HR ESMS showed them to be the methyl esters of three known arsenic fatty acids, namely AsFA 334, AsFA 362 and AsFA 390 (Table 3 and ESI Fig. S11†). This observation suggests that more complex arsenolipids, made-up of least one AsFA bound into an ester, were present in the original crude pyridine extract, and that these compounds underwent transesterification during the purification process using silica and methanol. A similar transesterification of arsenolipids with silica/methanol has been previously reported. ${ }^{39}$ These results suggested that the tuna brain may contain arsenic-containing phosphatidylcholines ${ }^{9}$ or perhaps arsenic-containing triglycerides; the latter arsenicals were thought to be present in fish oils of blue whiting, Micromesistius poutassou, ${ }^{39}$ and fish collected in the Pacific, ${ }^{40}$ and have recently been positively identified in the green alga Coccomyxa. ${ }^{41}$ HPLC/ICPMS analysis of purified extracts of muscle tissues showed a similar profile of arsenolipids, but the compounds were present at much lower concentrations than in brain tissues (Fig. 4C and ESI Fig. S9†).

The concentrations and distribution of individual arsenolipids detected in brain and muscle tissues of skipjack tuna are shown in Table 3. In the brain, 3.8-5.9 $\mathrm{mg}$ As per kg corresponding to $34-51 \%$ with a mean of $40 \%(n=5)$ of the total arsenic were arsenolipids, whereas in the muscle only a small portion of the arsenic, $0.3-0.8 \mathrm{mg}$ As per $\mathrm{kg}$ corresponding to 9$14 \%$ with a mean of $9 \%(n=5)$, was lipid-soluble arsenic.

Arsenic-containing hydrocarbons, the sum of AsHC 332, 360, 404 and 406 (AsHC 406 only detected in the brain), were identified as the main arsenolipids in brain and muscle tissues, with AsHC 332 being the most dominant, in both tissue types. AsFA 362 was detected as a minor constituent $(<1 \%$ of total As) in brain and muscle tissues. Arsenolipid profiles obtained by HPLC/ICPMS indicated generally low amounts of unesterified (free) AsFAs in both tissues. However, the AsFAs 334, 362 and 390 incorporated into more complex arsenolipid structures, and transformed to AsFA Me-esters in the course of the sample clean-up, contributed $\mathrm{ca} 20 \%$ to the total arsenolipid content in brain and muscle tissues.

Our results indicate a transfer of AsHCs across the fish blood-brain barrier and their accumulation in the brain since these species occur in muscle tissues at much lower concentrations. The transfer of AsHCs across the fish-blood brain barrier is consistent with a recent in vitro study of arsenolipids in the Caco-2 intestinal barrier model. ${ }^{21}$ In that study, AsHCs transferred efficiently across this barrier towards the bloodfacing side and showed a high intestinal bioavailability, suggesting that AsHCs have the potential to cross physiological barriers. Moreover, in the in vivo model Drosophila melanogaster $^{22}$ it was shown that AsHC 332 accumulated in the brain of the fruit fly. Compared to AsHCs, the AsFAs were transferred less efficiently across the intestinal barrier in the Caco- 2 model, although they showed a higher degree of presystemic metabolism. ${ }^{21}$ This latter aspect might be a reason for the low concentration of free AsFAs found in the fish brain in our study. Possibly, AsFAs after crossing the blood-brain barrier of the fish are either further metabolized or transformed to more complex arsenolipid structures or are reversibly exchanged with the blood facing side again. Also, it cannot be excluded that more complex lipid arsenicals, e.g. arsenic containingphosphatidylcholines or triglycerides, are biosynthesized earlier and then cross the blood-brain barrier as intact molecules. AsHCs, on the other hand, might be efficiently transferred across the blood-brain barrier owing to their more lipophilic nature, and once there they are stored unchanged, and consequently accumulated in the fat-rich tissue of the fish brain.

\section{Conclusions}

The applied method incorporating pyridine and an aqueous bicarbonate solution to sequentially extract both arsenolipids and water-soluble arsenic compounds from the same tissue sample is suitable for the investigation of arsenic compounds in tissue samples. By using this extraction method in combination with HPLC/mass spectrometry, we identified arsenic-containing hydrocarbons as major constituents in brain and muscle tissue of skipjack tuna (Katsuwonus pelamis). The brain also contained more complex arsenolipids incorporating an arsenic fatty acid; possibly these compounds were arsenic-containing phosphatidylcholines or arsenic-containing triglycerides. The arsenolipid concentrations were ten-fold higher in the brain compared to the muscle, indicating a transfer of these compounds across the fish blood-brain barrier and accumulation in the fish brain.

\section{Conflicts of interest}

There are no conflict of interests to declare.

\section{Acknowledgements}

We thank Empresa de Pesca de Aveiro S. A., Gafanha da Nazaré, Aveiro for all the technical personnel for the help and facilitating sampling. We thank also the Austrian Science Fund (FWF I12412-B21) and the German Research Foundation (DFG SCHW903/10-1) for financial support, and NAWI Graz for supporting the Graz Central Lab-Metabolomics. The authors acknowledge the financial support by the University of Graz.

\section{References}

1 V. Sele, J. J. Sloth, A.-K. Lundebye, E. H. Larsen, M. H. G. Berntssen and H. Amlund, Food Chem., 2012, 133, 618-630.

2 M. S. Taleshi, J. S. Edmonds, W. Goessler, M. J. RuizChancho, G. Raber, K. B. Jensen and K. A. Francesconi, Environ. Sci. Technol., 2010, 44, 1478-1483.

3 V. Sele, J. J. Sloth, K. Julshamn, K. Skov and H. Amlund, J. Trace Elem. Med. Biol., 2015, 30, 171-179.

4 E. Sadolin, Biochem. Z., 1928, 201, 323-331.

5 M. Morita and Y. Shibata, Chemosphere, 1988, 17, 1147-1152.

6 M. Stiboller, R. A. Glabonjat, G. Raber, K. B. Jensen and

K. A. Francesconi, Arsenolipids: An overview of current 
analytical aspects, Metallomics: Analytical Techniques and Speciation Methods, Wiley-VCH, New York, 1st edn, 2016, pp. 222-235.

7 A. Rumpler, J. S. Edmonds, M. Katsu, K. B. Jensen, W. Goessler, G. Raber, H. Gunnlaugsdottir and K. A. Francesconi, Angew. Chem., Int. Ed., 2008, 47, 26652667.

8 M. S. Taleshi, K. B. Jensen, G. Raber, J. S. Edmonds, H. Gunnlaugsdottir and K. A. Francesconi, Chem. Commun., 2008, 39, 4706-4707.

9 S. A. Viczek, K. B. Jensen and K. A. Francesconi, Angew. Chem., Int. Ed., 2016, 55, 5259-5262.

10 R. A. Glabonjat, G. Raber, K. B. Jensen, N. Guttenberger, K. Zangger and K. A. Francesconi, Angew. Chem., Int. Ed., 2017, 56, 11963-11965.

11 V. Sele, J. J. Sloth, B. Holmelid, S. Valdersnes, K. Skov and H. Amlund, Talanta, 2014, 121, 89-96.

12 K. O. Amayo, A. Raab, E. M. Krupp and J. Feldmann, Talanta, 2014, 118, 217-223.

13 U. Arroyo-Abad, J. Mattusch, S. Mothes, M. Moeder, R. Wennrich, M. P. Elizalde-González and F.-M. Matysik, Talanta, 2010, 82, 38-43.

14 S. Lischka, U. Arroyo-Abad, J. Mattusch, A. Kuehn and C. Piechotta, Talanta, 2013, 110, 144-152.

15 K. O. Amayo, A. Raab, E. M. Krupp, T. Marschall, M. Horsfall and J. Feldmann, J. Trace Elem. Med. Biol., 2014, 28, 131-137.

16 S. García-Salgado, G. Raber, R. Raml, C. Magnes and K. A. Francesconi, Environ. Chem., 2012, 9, 63-66.

17 A. Raab, C. Newcombe, D. Pitton, R. Ebel and J. Feldmann, Anal. Chem., 2013, 85, 2817-2824.

18 X. Yu, C. Xiong, K. B. Jensen, R. A. Glabonjat, M. Stiboller, G. Raber and K. A. Francesconi, Food Chem., 2018, 240, 817-821.

19 S. Meyer, M. Matissek, S. M. Müller, M. S. Taleshi, F. Ebert, K. A. Francesconi and T. Schwerdtle, Metallomics, 2014, 6, 1023-1033.

20 S. Meyer, J. Schulz, A. Jeibmann, M. S. Taleshi, F. Ebert, K. A. Francesconi and T. Schwerdtle, Metallomics, 2014, 6, 2010-2014, http://pubs.rsc.org/en/content/articlepdf/2014/ $\mathrm{mt} / \mathrm{c} 4 \mathrm{mt} 00249 \mathrm{k}$.

21 S. Meyer, G. Raber, F. Ebert, M. S. Taleshi, K. A. Francesconi and T. Schwerdtle, Mol. Nutr. Food Res., 2015, 59, $2044-2056$.

22 A.-C. Niehoff, J. Schulz, J. Soltwisch, S. Meyer, H. Kettling, M. Sperling, A. Jeibmann, K. Dreisewerd,
K. A. Francesconi, T. Schwerdtle and U. Karst, Anal. Chem., 2016, 88, 5258-5263.

23 M. S. Taleshi, R. K. Seidler-Egdal, K. B. Jensen, T. Schwerdtle and K. A. Francesconi, Organometallics, 2014, 33, 1397-1403.

24 R. A. Glabonjat, G. Raber, K. B. Jensen, J. Ehgartner and K. A. Francesconi, Anal. Chem., 2014, 86, 10282-10287.

25 J. Folch, M. Lees and G. H. S. Stanley, J. Biol. Chem., 1957, 226, 497-509.

26 E. G. Blight and W. J. Dyer, Can. J. Biochem. Physiol., 1959, 37, 911-917.

27 V. Matyash, G. Liebisch, T. V. Kurzchalia, A. Shevchenko and D. Schwudke, J. Lipid Res., 2008, 49, 1137-1146.

28 Á. H. Pétursdóttir, J. Rodrigues de Jesus, H. Gunnlaugsdóttir and J. Feldmann, J. Anal. At. Spectrom., 2018, 33, 102-110.

29 G. Schwedt, Chromatographische Trennmethoden. Theoretische Grundlagen, Techniken und analytische Anwendungen, Georg Thieme Verlag, Stuttgart, 1986.

30 C.-Y. Chen, Y.-T. Chen, K.-S. Chen, C.-C. Hsu, L.-L. Liu, H.-S. Chen and M.-H. Chen, Mar. Pollut. Bull., 2018, 129, 186-193.

31 R. Núñez, M. Á. García, J. Alonso and M. J. Melgar, Sci. Total Environ., 2018, 627, 322-331.

32 G. Raber, N. Stock, P. Hanel, M. Murko, J. Navratilova and K. A. Francesconi, Food Chem., 2012, 134, 524-532.

33 W. R. Cullen and K. J. Reimer, Chem. Rev., 1989, 89, 713-764. 34 K. A. Francesconi, J. S. Edmonds and M. Barnes, Arsenic in the sea, Oceanography and Marine Biology-An Annual Review, CRC Press, Boca Raton, FL, 1st edn, 1993, vol. 31, pp. 111-151.

35 F. Challenger, Chem. Rev., 1954, 36, 315-361.

36 V. Taylor, B. Goodale, A. Raab, T. Schwerdtle, K. Reimer, S. Conklin, M. R. Karagas and K. A. Francesconi, Sci. Total Environ., 2017, 580, 266-282.

37 E. Schmeisser, A. Rumpler, M. Kollroser, G. Rechberger, W. Goessler and K. A. Francesconi, Angew. Chem., Int. Ed., 2005, 45, 150-154.

38 E. Schmeisser, W. Goessler and K. A. Francesconi, Anal. Bioanal. Chem., 2006, 385, 367-376.

39 M. S. Taleshi, G. Raber, J. S. Edmonds, K. B. Jensen and K. A. Francesconi, Sci. Rep., 2014, 4, 7492-7499.

40 É. R. Pereira, J. F. Kopp, A. Raab, E. M. Krupp, J. d. C. Menoyo, E. Carasek, B. Welz and J. Feldmann, J. Anal. At. Spectrom., 2016, 31, 1836-1845.

41 T. Řezanka, L. Nedbalová, D. Barcytè, M. Vítová and K. Sigler, Phytochemistry, 2019, 164, 243-251. 